\title{
Uji ketahanan fatik aluminium hasil remelting piston bekas menggunakan metode pengecoran centrifugal casting
}

\author{
Eko Nugroho', Eko Budiyanto2 ${ }^{\star}$, Rubi Kurniawan³, Joko Sumosusilo ${ }^{4}$ \\ Jurusan Teknik Mesin, Fakultas Teknik, Universitas Muhammadiyah Metro \\ Prodi Teknik Mesin, Fakultas Teknik, Universitas Muhammadiyah Metro ${ }^{3,4}$ \\ Jl. Ki Hajar Dewantara 15 A Kota Metro, Lampung, Indonesia \\ ${ }^{*}$ Coresponding author: eko_budiyanto99@yahoo.com
}

\begin{abstract}
Aluminum is one of the non-ferrous metals that are most widely used in the engineering field due to it has mild properties and is resistant to corrosion, but aluminum waste such as used pistons that are damaged or not utilized as an proper resource, on the other hand, that this process is very potential due to it uses a used piston that is not used, and is expected to have a better economic value by doing remelting and centrifugal casting to the used piston. This study aims to determine the value of the fatigue cycle of the used piston which is remelting and printed using the centrifugal casting method by using variations in the pouring temperature and die temperature and rotation variations. Based on the tests conducted using pouring temperature variations and rotation speed are as follows: best cycle value at $250 \mathrm{rpm}$ variation is at pouring temperature $600^{\circ} \mathrm{C}$ with a value of $76000 \mathrm{~N}$, and the lowest is at room temperature of $750^{\circ} \mathrm{C}$ with a value of $32000 \mathrm{~N}$, best cycle at a variation of $500 \mathrm{rpm}$ is at a pouring temperature of $700^{\circ} \mathrm{C}$ with a value of $40000 \mathrm{~N}$, and the lowest is at a room temperature of $660^{\circ} \mathrm{C}$ with a value of $12000 \mathrm{~N}$. The best cycle value at a variation of $750 \mathrm{rpm}$ is at a pouring temperature of $750^{\circ} \mathrm{C}$ with a value of $16000 \mathrm{~N}$, and the lowest is at room temperature $660^{\circ} \mathrm{C}$ with a value of $10000 \mathrm{~N}$. While the results of subsequent tests conducted using variations in die temperature and rotation speed are as follows: the best cycle value at $250 \mathrm{rpm}$ variation is at a print temperature of $350^{\circ} \mathrm{C}$ with a value of $17400 \mathrm{~N}$, and the lowest is at room temperature of $250^{\circ} \mathrm{C}$ with a value of $8370 \mathrm{~N}$. The best cycle value at a variation of $500 \mathrm{rpm}$ is at a print temperature of $350^{\circ} \mathrm{C}$ with a value of $67760 \mathrm{~N}$, and the lowest is at a room temperature of $250^{\circ} \mathrm{C}$ with a value of $22850 \mathrm{~N}$. The best cycle value at a variation of $750 \mathrm{rpm}$ is at a print temperature of $350^{\circ} \mathrm{C}$ with a value of $75170^{\circ} \mathrm{C}$. and the lowest is at room temperature of $250^{\circ} \mathrm{C}$ with a value of $28940 \mathrm{~N}$.
\end{abstract}

Keywords: Centrifugal casting, fatigue test, remelting, used piston, aluminum, cycle value.

\begin{abstract}
Abstrak
Aluminium merupakan salah satu logam non ferrous yang paling banyak digunakan dalam bidang keteknikan karena memiliki sifat yang ringan dan tahan terhadap korosi, namun limbah alumunium semisal piston bekas yang rusak atau yang tidak dimanfaatkan menjadi sumber daya yang menarik, disisi lain bahwa proses ini sangat potential, karna menggunakan piston bekas yang sudah tidak dipakai, dan diharapkan akan memiliki nilai ekonomis yang lebih baik dengan melakukan remelting dan centrifugal casting kepada piston bekas. Tujuan dari penelitian ini adalah untuk mengetahui nilai siklus fatik dari piston bekas yang di remelting kembali dan dicetak dengan metode centrifugal casting dengan menggunakan variasi temperatur tuang dan temperatur cetak serta variasi putaran. Dari pengujian yang dilakukan dengan menggunakan variasi temperatur tuang dan kecepatan putar adalah sebagai berikut : nilai siklus paling baik pada variasi $250 \mathrm{rpm}$ adalah pada temperatur tuang $600^{\circ} \mathrm{C}$ dengan nilai sebesar $76000 \mathrm{~N}$, dan yang paling rendah adalah pada temperatur ruang $750^{\circ} \mathrm{C}$ dengan nilai sebesar 32000 N. Nilai siklus paling baik pada variasi $500 \mathrm{rpm}$ adalah pada
\end{abstract}


temperatur tuang $700^{\circ} \mathrm{C}$ dengan nilai sebesar $40000 \mathrm{~N}$, dan yang paling rendah adalah pada temperatur ruang $660 \mathrm{oC}$ dengan nilai sebesar $12000 \mathrm{~N}$. Nilai siklus paling baik pada variasi $750 \mathrm{rpm}$ adalah pada temperatur tuang $750^{\circ} \mathrm{C}$ dengan nilai sebesar $16000 \mathrm{~N}$, dan yang paling rendah adalah pada temperatur ruang $660^{\circ} \mathrm{C}$ dengan nilai sebesar $10000 \mathrm{~N}$. Sementara hasil pengujian selanjutnya yang dilakukan dengan menggunakan variasi temperatur cetak dan kecepatan putar adalah sebagai berikut : nilai siklus paling baik pada variasi $250 \mathrm{rpm}$ adalah pada temperatur cetak $350^{\circ} \mathrm{C}$ dengan nilai sebesar $17400 \mathrm{~N}$, dan yang paling rendah adalah pada temperatur ruang $250^{\circ} \mathrm{C}$ dengan nilai sebesar $8370 \mathrm{~N}$. Nilai siklus paling baik pada variasi $500 \mathrm{rpm}$ adalah pada temperatur cetak $350^{\circ} \mathrm{C}$ dengan nilai sebesar $67760 \mathrm{~N}$, dan yang paling rendah adalah pada temperatur ruang $250^{\circ} \mathrm{C}$ dengan nilai sebesar $22850 \mathrm{~N}$. Nilai siklus paling baik pada variasi $750 \mathrm{rpm}$ adalah pada temperatur cetak $350^{\circ} \mathrm{C}$ dengan nilai sebesar $75170^{\circ} \mathrm{C}$. dan yang paling rendah adalah pada temperatur ruang $250^{\circ} \mathrm{C}$ dengan nilai sebesar $28940 \mathrm{~N}$.

Kata kunci : Centrifugal casting, uji fatik, remelting, piston bekas, alumunium, nilai siklus.

\section{Pendahuluan}

Industri pengecoran yang menjadi sektor pendukung utama bagi industri otomotif, terutama pembuatan suku cadangnya. Pengecoran dilakukan sekitar tahun 4000 sebelum masehi. Coran dibuat dari logam yang dicairkan, dituang kedalam cetakan, kemudian dibiarkan mendingin dan membeku. Oleh karna itu sejarah pengecoran dimulai ketika orang mengetahui bagaimana membuat cetakan. Awal penggunaan logam yaitu ketika orang membuat perhiasan dari emas ataupun perak tempaan hal itu kemungkinan karena logam logam ini terdapat di alam dalam keadaan murni sehingga dengan mudah orang dapat menempanya [1].

Aluminium merupakan salah satu logam non ferrous yang paling banyak digunakan dalam bidang keteknikan karena memiliki sifat yang ringan dan tahan terhadap korosi. Biasanya paduan aluminium dipadukan dengan unsur-unsur antara lain: $\mathrm{Cu}, \mathrm{Si}, \mathrm{Mg}, \mathrm{Zn}, \mathrm{Mn}$, Ni dan masih banyak unsur paduan lainnya. Aluminium mempunyai titik leleh $660^{\circ} \mathrm{C}$ dan masa jenis $2,75 \mathrm{~kg} / \mathrm{m}^{3}$. Sebanding dengan penggunaannya yang bermacammacam maka limbah aluminium banyak ditemukan dan bernilai ekonomis yang lebih rendah dari pada bahan lain [2].

Pengecoran centrifugal casting merupakan metode pengecoran dimana logam cair membeku di dalam cetakan yang berputar. Centrifugal casting lebih baik dari pada static porosity dan shrinkage porosity. Gaya sentrifugal pada centrifugal casting ini lebih baik dari pada metode gravitasi karna gaya sentrifugal mampu memampatkan logam cair sehingga dihasilkan logam yang lebih baik dengan cacat pengecoran seperti porositas yang relatif lebih kecil, sehingga akan berdampak sifat fisis dan mekanis material tersebut dan juga akan berdampak pada karakteristik perambatan retak fatik [3].

Remelting merupakan salah satu metode pengecoran daur ulang dengan melebur kembali material logam yang telah ada. Keuntungan dari remelting ini diantaranya harganya yang relatif murah dan dapat dilakukan oleh industri meskipun hanya skala home industry. Reject material juga lebih efisien memanfaatkan bahan aluminium yang telah ada. Hasilnya tidak sebagus pengecoran dengan bahan murni namun masih dapat digunakan untuk benda coran yang mendapat perlakuan gaya yang tidak begitu besar [4].

Suhu penuangan dalam proses pengecoran merupakan salah satu hal yang sangat berpengaruh penting, karena akan sangat berpengaruh dalam hasil cetakan. Suhu tuang aluminium yang terlalu rendah maka rongga cetakan tidak akan terisi penuh dimana saluran masuk akan terbuka terlebih dahulu, dan apabila suhu tuang 
terlalu tinggi maka hal ini akan mengakibatkan penyusutan dan kehilangan akan keakuratan dimensi coran. Suhu tuang pada aluminium biasanya terdapat pada range $675-790^{\circ} \mathrm{C}$ dan harus tetap diperhatikan pada saat penuangan [4].

Selain itu temperatur cetakan juga sangat berpengaruh terhadap laju pendinginan suatu coran, karna temperatur dapat mengakibatkan cepat atau lambatnya suatu pendinginan atau pembekuan pada coran dan dapat mempengaruhi sifat fisik suatu material coran [5].

Uji fatik atau lelah pada penelitian ini adalah uji lentur putar yang hasilnya adalah umur lelah dan besar tegangan yang diberikan serta perkiraan tegangan batas. Kegagalan uji fatik ada 3 fasa yaitu: awal retak (initiation), perambatan retak (crack propogation), dan perpatahan akhir (fracture frailure). Lebih dari $90 \%$ penyebab kegagalan mekanik adalah disebabkan oleh kelelahan (fatik) [6].

Sifat mekanis yang dicari dalam penelitian ini adalah uji ketahanan fatik, Sebelum melakukan uji fatik terlebih dahulu melakukan remelting dan uji tarik, dilakukan uji tarik karena untuk mengetahui nilai Yiels Strength. Uji fatik didefinisikan sebagai jumlah siklus kegagalan pada pembebanan tertentu dan memperoleh data yang dapat digunakan untuk memprediksi umur pakai bahan.

Dalam penelitian remelting aluminium scrap atau piston bekas ini diharapkan nantinya bahan yang sudah tidak dapat digunakan lagi seperti piston bekas ini dapat dimanfaatkan kembali.

\section{Metode Penelitian}

Dalam penelitian ini ada beberapa peralatan dan bahan yang digunakan untuk melakukan uji ketahanan fatik aluminium hasil remelting piston bekas menggunakan metode pengecoran sentrifugal casting. Adapun alat yang digunakan adalah tungku pelebur, jangka sorong, thermometer, tachometer, mesin bubut, mesin uji fatik, mesin centrifugal casting vertical.
Dalam penelitian ini pengumpulan dan pengambilan data dilakukan dengan melalui beberapa metode :

1. Data primer, yaitu data-data yang diperoleh melalui observasi langsung yaitu pengambilan data selama proses centrifugal casting dilakukan dengan variasi temperatur tuang dan temperatur cetak serta variasi kecepatan putar, kemudian melakukan uji fatik.

2. Data sekunder, yaitu pengumpulan data yang diperoleh dari hasil penelusuran terhadap berbagai literatur yang sesuai dengan materi penelitian.

\section{Hasil dan Pembahasan}

Dari hasil pengujian dan perhitungan diperoleh grafik siklus dengan variasi temperatur tuang dan rpm yaitu sebagai berikut :

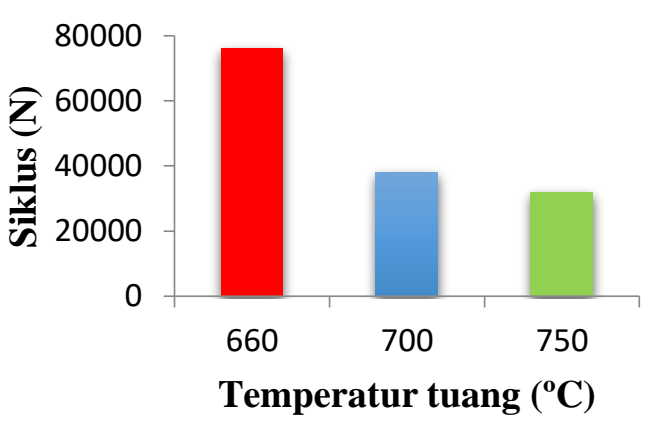

Gambar 1. grafik hasil pengujian fatik dengan siklus putaran $250 \mathrm{rpm}$.

Dalam pengujian fatik dengan pembebanan dan putaran yang sama pada setiap spesimen dapat dilihat pada gambar diatas, semakin tinggi temperatur tuang dengan putaran $250 \mathrm{rpm}$ pada sentrifugal casting spesimen mengalami kegagalan pada pembebanan yang sama pada setiap spesimen. Bisa dilihat yg paling baik nilai lelahnya adalah pada temperatur tuang $660^{\circ} \mathrm{C}$ dengan nilai siklus sebesar $=76000$ $\mathrm{N}$ dengan catatan waktu 76 menit. 


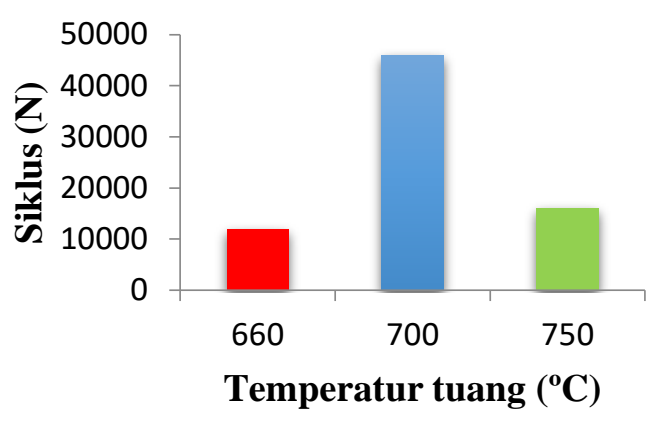

Gambar 2. grafik hasil pengujian fatik dengan siklus putaran $500 \mathrm{rpm}$

Dalam pengujian fatik dengan pembebanan dan putaran yang sama pada setiap spesimen dapat dilihat pada gambar 2. Semakin tinggi temperatur tuang dengan putaran $500 \mathrm{rpm}$ pada sentrifugal casting spesimen mengalami kegagalan pada pembebanan yang sama pada setiap spesimen. Bisa dilihat yg paling baik nilai lelahnya adalah pada temperatur tuang $700^{\circ} \mathrm{C}$. Dengan nilai siklus $=46000 \mathrm{~N}$ dengan catatan waktu 46 menit.

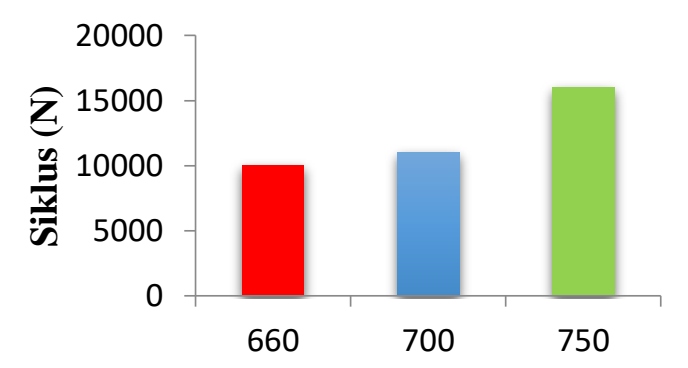

Temperatur tuang $\left({ }^{\circ} \mathrm{C}\right)$

Gambar 3. grafik hasil pengujian fatik dengan siklus putaran $750 \mathrm{rpm}$.

Dalam pengujian fatik dengan pembebanan dan putaran yang sama pada setiap spesimen dapat dilihat pada Gambar 3. Nilai siklus yang paling baik terjadi pada temperatur tuang $750^{\circ} \mathrm{C}$ dengan nilai siklus sebesar $=16000 \mathrm{~N}$ dengan catatan waktu 16 menit.

Dari hasil pengujian dan perhitungan diperoleh grafik siklus dengan variasi temperatur cetak dan rpm yaitu sebagai berikut :

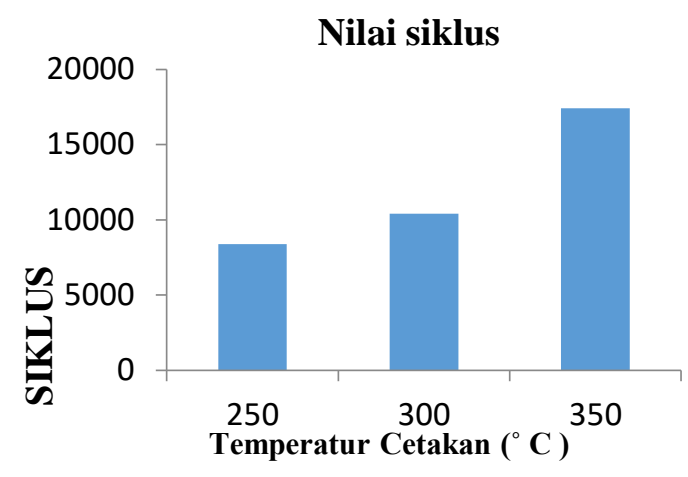

Gambar 4. Grafik variasi putaran Centrifugal casting $250 \mathrm{rpm}$

Dari Gambar 4. diatas dengan variasi putaran Centrifugal casting $250 \mathrm{rpm}$ dan temperatur cetakan : $250^{\circ} \mathrm{C}, 300^{\circ} \mathrm{C}$ dan $350^{\circ} \mathrm{C}$ bisa dilihat bahwa nilai siklus yang lebih baik adalah temperatur cetakan $350^{\circ}$ $\mathrm{C}$ dimana grafik menunjukan hasil siklus $=$ $17400 \mathrm{~N}$ maka dari hasil pengujian fatik grafik diatas nilai lelahnya yang paling baik pada temperatur $350^{\circ} \mathrm{C}$.

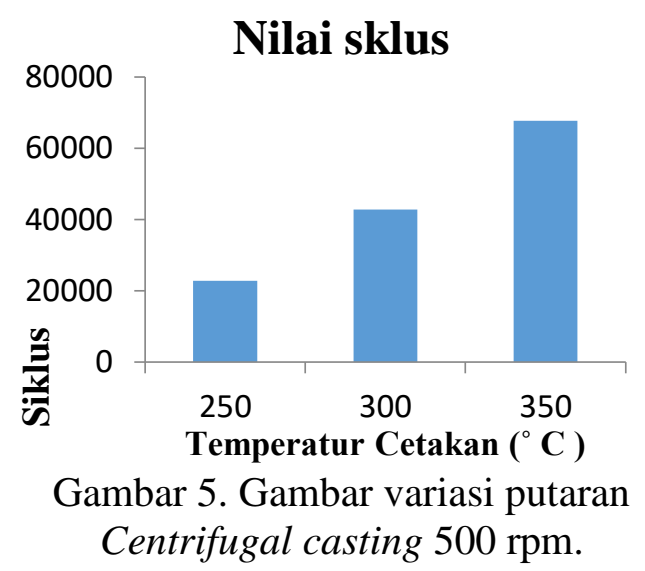

Dari Grafik 4.2 diatas dengan variasi putaran Centrifugal casting $500 \mathrm{rpm}$ dan temperatur cetakan : $250^{\circ} \mathrm{C}, 300^{\circ} \mathrm{C}$ dan $350^{\circ} \mathrm{C}$ bisa dilihat bahwa nilai siklus yang lebih baik adalah temperatur cetakan $350^{\circ}$ $\mathrm{C}$ dimana grafik menunjukan hasil siklus $=$ $67760 \mathrm{~N}$ maka dari hasil pengujian fatik grafik diatas nilai lelahnya yang paling baik pada temeratur $350^{\circ} \mathrm{C}$. 


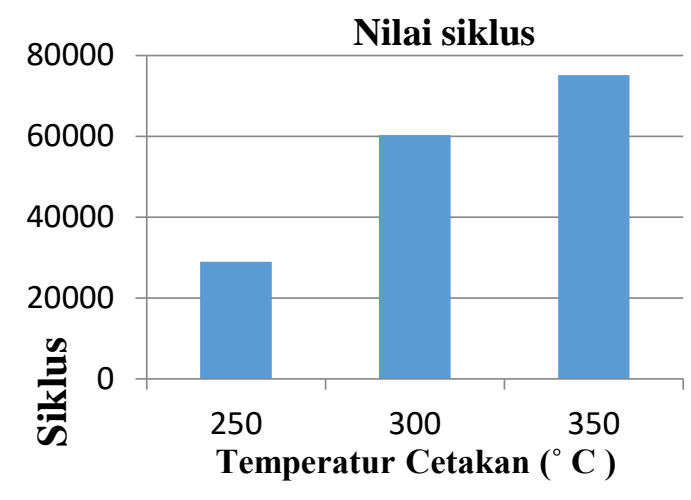

Gambar grafik 6. variasi putaran Centrifugal casting $750 \mathrm{rpm}$

Dari Gambar 6. diatas dengan variasi putaran Centrifugal casting 750 rpm dan temperatur cetakan : $250^{\circ} \mathrm{C}, 300^{\circ}$ $\mathrm{C}$ dan $350^{\circ} \mathrm{C}$ bisa dilihat bahwa nilai siklus yang lebih baik adalah temperatur cetakan $350^{\circ} \mathrm{C}$ dimana grafik menunjukan hasil siklus $=75170 \mathrm{~N}$ maka dari hasil pengujian fatik grafik diatas nilai lelahnya yang paling baik pada temperatur $350^{\circ} \mathrm{C}$.

\section{Kesimpulan}

Dari hasil penelitian yang telah dilakukan dengan melakukan variasi temperatur tuang dan rpm didapatkan nilai siklus paling baik pada variasi $250 \mathrm{rpm}$ adalah pada temperatur tuang $600^{\circ} \mathrm{C}$ dengan nilai sebesar $76000 \mathrm{~N}$, dan yang paling rendah adalah pada temperatur ruang $750^{\circ} \mathrm{C}$ dengan nilai sebesar 32000 N. Nilai siklus paling baik pada variasi $500 \mathrm{rpm}$ adalah pada temperatur tuang $700^{\circ} \mathrm{C}$ dengan nilai sebesar $40000 \mathrm{~N}$, dan yang paling rendah adalah pada temperatur ruang $660^{\circ} \mathrm{C}$ dengan nilai sebesar 12000 N. Nilai siklus paling baik pada variasi $750 \mathrm{rpm}$ adalah pada temperatur tuang $750^{\circ} \mathrm{C}$ dengan nilai sebesar $16000 \mathrm{~N}$, dan yang paling rendah adalah pada temperatur ruang $660^{\circ} \mathrm{C}$ dengan nilai sebesar 10000 $\mathrm{N}$.

Dari hasil penelitian yang telah dilakukan dengan variasi temperatur cetak dan rpm didapatkan nilai siklus paling baik pada variasi $250 \mathrm{rpm}$ adalah pada temperatur cetak $350^{\circ} \mathrm{C}$ dengan nilai sebesar $17400 \mathrm{~N}$, dan yang paling rendah adalah pada temperatur ruang $250^{\circ} \mathrm{C}$ dengan nilai sebesar 8370 N. Nilai siklus paling baik pada variasi $500 \mathrm{rpm}$ adalah pada temperatur cetak $350^{\circ} \mathrm{C}$ dengan nilai sebesar $67760 \mathrm{~N}$, dan yang paling rendah adalah pada temperatur ruang $250^{\circ} \mathrm{C}$ dengan nilai sebesar $22850 \mathrm{~N}$. Nilai siklus paling baik pada variasi $750 \mathrm{rpm}$ adalah pada temperatur cetak $350^{\circ} \mathrm{C}$ dengan nilai sebesar $75170^{\circ} \mathrm{C}$. dan yang paling rendah adalah pada temperatur ruang $250^{\circ} \mathrm{C}$ dengan nilai sebesar $28940 \mathrm{~N}$.

\section{Referensi}

[1]. Prof. Ir. Tata Surdia M.S. Met. E. \& Prof. Dr. Kenji chijiiwa 1975 Association far International Technical Promotion. PT Pradnya Paramita Jalan Bunga 8 - 8A Jakarta 13140..

[2]. Ihsan, T., Edwin, T. and Irawan, R. O. 2016. "Analisa Risiko K3 Dengan Metode Hirarc Pada Area Produksi Pt Cahaya Murni Andalas Permai”. Padang: Universitas Andalas. Jurnal Kesehatan Masyarakat Andalas, Vol. 10 available at: https;//jurnal.fkm.unand.ac.id/index. php/jkma/article/view/204.

[3]. Nugroho dan hudawan. 2016. Pengaruh variasi putaran cetakan dan penambahan inokulan Ti-B pada sentrifugal casting terhadap sifat mekanis dan struktur mikro paduan aluminium A356.0. Jurusan Teknik Mesin, Fakultas Teknik, Universitas Muhammadyah Metro Lampung.

[4]. Agus zainudin. 2017. Analisa Uji Ketahanan Fatik Dengan Type Rotary Bending Pada Aluminium Scrap Hasil Remelting Piston Bekas Terhadap Variasi Beban,. Jurusan Teknik Mesin, Fakultas Teknik, Universitas Muhammadiyah Metro.

[5]. Wardoyo, J.T., 2012, “ Pengaruh Temperatur Tuang dan Temperatur Cetakan proses HPDC terhadap kekerasan dan Porositas Bahan ADC 12 untuk Sepatu Rem Sepeda 
Motor", Tesis S-2 Teknik Mesin UNDIP.

[6]. Pratowo Bambang. Novran. Apriansyah. 2016. Analisa Kekuatan Fatik Baja Karbon Rendah SC10 Dengan Tipe Rotary Bending. Teknik Mesin. Fakultas Teknik. Universitas Bandar Lampung. 